\title{
Impact of an integrated control campaign on tsetse populations in Burkina Faso
}

\author{
Lassané Percoma ${ }^{1 *}$, Adama Sow ${ }^{1,2,3}$, Soumaïla Pagabeleguem ${ }^{1,4}$, Ahmadou H. Dicko ${ }^{5}$, Oumarou Serdebéogo ${ }^{1}$, \\ Mariam Ouédraogo ${ }^{6}$, Jean-Baptiste Rayaissé ${ }^{2}$, Jérémy Bouyer ${ }^{4,7}$, Adrien M. G. Belem ${ }^{8}$ and Issa Sidibé ${ }^{1,2}$
}

\begin{abstract}
Background: Tsetse flies are the sole vectors of human and animal trypanosomosis. In Burkina Faso, a project aiming to create zones free of tsetse flies and trypanosomosis was executed from June 2006 to December 2013. After the determination of tsetse distribution in the intervention area from December 2007 to November 2008, the control campaign was launched in November 2009 and ended in December 2013. The goal was to eliminate tsetse flies from $40,000 \mathrm{~km}^{2}$ of area, through an integrated control campaign including insecticide targets, traps and cattle, sequential aerial treatment (SAT) and the mass treatment of livestock using trypanocides. The campaign involved assistance of the beneficiary communities at all the steps of the control strategy with insecticide impregnated targets.
\end{abstract}

Methods: This study was carried out to assess the impact of the control project on tsetse apparent density per trap per day (ADT). To evaluate the effectiveness of tsetse control, 201 sites were selected based on the baseline survey results carried out from December 2007 to November 2008. These sites were monitored bi-monthly from January 2010 to November 2012. At the end-of-study in 2013 a generalized entomological survey was carried out in 401 infested sites found during the longitudinal survey done before the control. Barrier and tsetse persistence areas were treated by ground spraying and evaluated. Controls were also done before and after aerial spraying.

Results: In the insecticide-impregnated target area, the control showed that ADT of tsetse flies declined from 10.73 (SD 13.27) to 0.43 (SD 2.51) fly/trap/day from the third month of campaign onwards $(P<0.0001)$ and remained low thereafter. At the end of the campaign in 2013, an $83 \%$ reduction of ADT was observed for Glossina palpalis gambiensis and a $92 \%$ reduction for G. tachinoides. Tsetse flies were captured only in 29\% of the sites found infested in 2008.

Conclusions: Tsetse flies could be suppressed efficiently but their elimination from the targeted area may require the use integrated methods including the Sterile Insect Technique, which is programmed through the development of the Pan African Tsetse and Trypanosomiasis Eradication Campaign (PATTEC Burkina) insectarium. The challenge will remain the sustainability of the achievement.

Keywords: Tsetse fly, Glossina, Trypanosomosis, Eliminate, Target, Control, Burkina Faso

\section{Background}

The national component of the Pan African Tsetse and Trypanosomosis Eradication Campaign (PATTEC) is the most important tsetse control program ever implemented in Burkina Faso. Its intervention area covers $96,600 \mathrm{~km}^{2}$ for control and $40,000 \mathrm{~km}^{2}$ for total eradication. The current program took advantage of lessons learned from the past and was based on a holistic approach of trypanosomosis

\footnotetext{
* Correspondence: percomalas@yahoo.fr

${ }^{1}$ Insectarium de Bobo-Dioulasso - Campagne d'Eradication des Tsé-tsé et

Trypanosomoses (IBD-CETT), Bobo-Dioulasso 01 BP 1087, Burkina Faso

Full list of author information is available at the end of the article
}

control. Indeed, the main reason for failure of past campaigns in Burkina Faso was the sustainability of the achievement. In the 1980s and 1990s, numerous tsetse control projects were implemented, namely in the agropastoral zone of Sidéradougou [1] and the pastoral zone of Yalé $[2,3]$. In these campaigns, beneficiary communities, farmers and public Authorities did not continue the efforts after the projects ended. Consequently, the tsetse cleared areas were re-invaded rapidly by tsetse and the trypanosomosis incidence regained similar levels as before the projects implementation. The successes and failures of these projects have been discussed previously [4]. 
For tsetse control, an integrated pest management, including impregnated targets and traps, live baits (insecticide treated cattle), ground spraying and sequential aerial treatment (SAT), was used by PATTEC Burkina. Barriers were used between treated and untreated areas. The campaign funded the mass treatment of livestock against trypanosomosis. One of the most important components of this campaign was the involvement of beneficiary communities.

This study aimed to describe the various tsetse fly control actions carried out and to assess their effectiveness to control tsetse and trypanosomosis.

\section{Methods}

\section{Study area}

The study was carried out in the regions of Boucle du Mouhoun, Hauts Bassins, Centre-Ouest and Sud-Ouest (aerial spraying area), covering the PATTEC intervention area of Burkina Faso (Fig. 1). These regions are mainly rural, where most of the population earns their life by crop production and livestock husbandry [5]. They host almost 700,000 cattle, double this number of small ruminants, and tens of thousands of pigs, horses and donkeys [6]. The region is one of the areas in the country where trypanosomosis is the most prevalent [7]. The Mouhoun River crosses the region over almost $280 \mathrm{~km}$, describing a loop. The main river is joined by permanent secondary tributaries. This explains the abundance of riverine tsetse species, Glossina palpalis gambiensis and G. tachinoides [8]. The entomological surveys funded by PATTEC Burkina and conducted before the control measures showed that the apparent abundance per trap was high, especially on the main river and permanent tributaries, where more than 92 tsetse/trap/day were observed in some sites [9].

\section{Trypanosomosis and tsetse control strategies Communities' awareness and their participation}

Tsetse control involved communities' commitment $[4,10]$. For the current PATTEC Burkina campaign, the communities were sensitized on trypanosomosis socio-economic impact and the different control methods. During the entomological baseline surveys, they were used as guides. After the entomological baseline survey and during the control, populations of 300 infested villages, grouped in 53 village clusters, were regularly informed about the results obtained and awareness was stimulated. In each village, at least 5 people were chosen as auxiliaries for PATTEC Burkina field teams in order to assist them in the deployment and surveillance of targets impregnated with insecticide. They carried out an important part of the field work, including the setting of insecticide impregnated targets during the dry season and their withdrawal or moving during the rainy season. Additionally, four supervisor teams of barriers were created in conjunction with the municipal authorities of these barriers and equipped with some working materials including bicycles, boots, wires, cutters, etc.

\section{Insecticide impregnated targets}

Targets used for the control campaign were manufactured by the Vestergaard Frandsen Company (Lausanne,

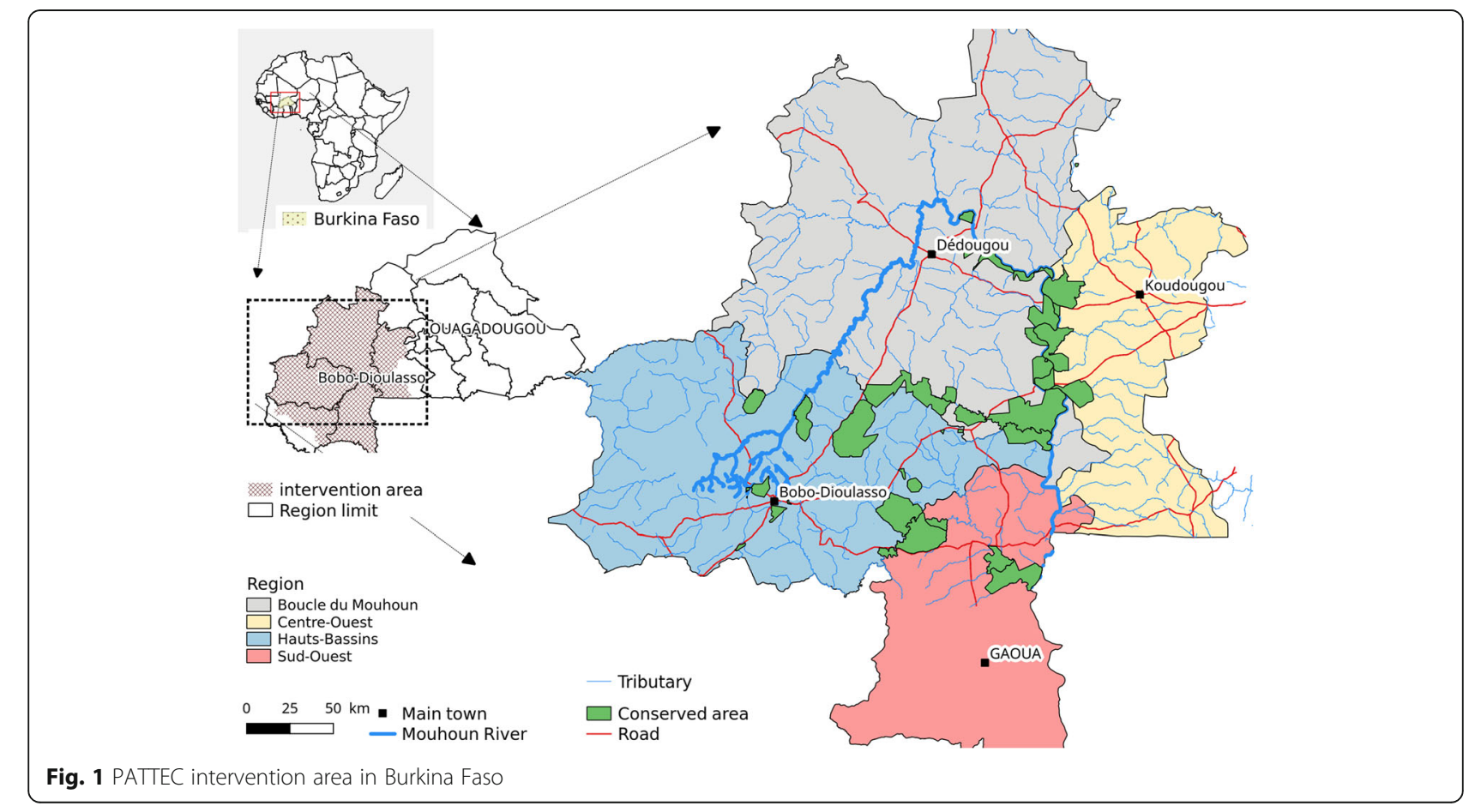


Switzerland). They were made with polyester material. Targets consisted of a central blue rectangular piece $(50 \times 100 \mathrm{~cm})$ flanked by two black strips $(25 \times 100 \mathrm{~cm})$; hence, the total surface of a target was $1 \mathrm{~m}^{2}$. According to the manufacturer, those deltamethrin impregnated targets are effective against tsetse for 2 years. All rivers and tributaries found infested during the baseline entomological survey were covered by impregnated targets and each target deployed was geo-referenced according to the Universal Transverse Mercator coordinate system (UTM). Targets deployed remained on the field all year.

From November 2009 to April 2010, 21,360 impregnated targets were deployed (Fig. 2). The targets were set alternatively on one of the two banks of the main river and some main tributaries, and on one bank of the small tributaries, at distances of 50-100 m between targets. Sometimes selective bush clearing was necessary to increase the target visibility. Targets were fixed either on metallic poles or hung on tree branches over the river.

To calculate target density per $\mathrm{km}, 5 \times 2 \mathrm{~km}$ grids were realized along covered rivers. The density per $\mathrm{km}$ of river was obtained by the formula: $\frac{\text { Number of targets of each grid }}{\text { length of river } \epsilon \text { each grid }}$ and $\mathrm{km}^{2}$ of surface by $\frac{\text { Number of target } \epsilon \text { each grid }}{\text { area of a grid }\left(\mathrm{km}^{2}\right)}$ by spatial analyses of the data extracted from a relational database.

In 2011 and 2012, 15,562 and 3726 targets were deployed respectively to replace the ones which disappeared or to reinforce them. In total, from November 2009 to 2012, 42,138 targets were deployed.

\section{Barriers}

Previous genetic studies showed that the target area was not isolated [11-13]. Following the recommendations of Kgori et al. [14], the target area was thus protected from re-invasion using artificial barriers. Two barriers were built from May, 31th to June, 04th 2010 on the two branches of the Mouhoun River (ascendant and descendant) by impregnated targets deployment (Fig. 2). On the ascendant branch, the "Satiri" barrier was built with 483 impregnated targets and 78 impregnated traps (biconical and monoconical) on a distance of $8.3 \mathrm{~km}$ along the main river and 293 impregnated targets and 39 impregnated traps on $6.8 \mathrm{~km}$ along the tributaries. On the descendant branch, the "Fara" barrier was made with 95 targets on $9.64 \mathrm{~km}$ of Mouhoun River and 74 targets on $5.53 \mathrm{~km}$ of tributaries. This barrier had benefited of sequential aerial treatment done between Ghana and Burkina Faso. The local supervisors maintained regularly the barriers. Destroyed targets were replaced twice a year at the beginning (June) and end of the rainy season (November-December) by PATTEC technicians.

\section{Sequential aerial treatment}

Sequential aerial treatment was carried out jointly with the counterpart of Ghana [15]. The main objective was to limit or to avoid the re-invasion between the two countries intervention areas. It concerned the descendant part of the Mouhoun River (Fig. 3) on $114 \mathrm{~km}$ and $138 \mathrm{~km}$ on Sissili River. Seven $\mathrm{km}$ were sprayed on both sides of every bank. Aerial spraying and targets covered a same

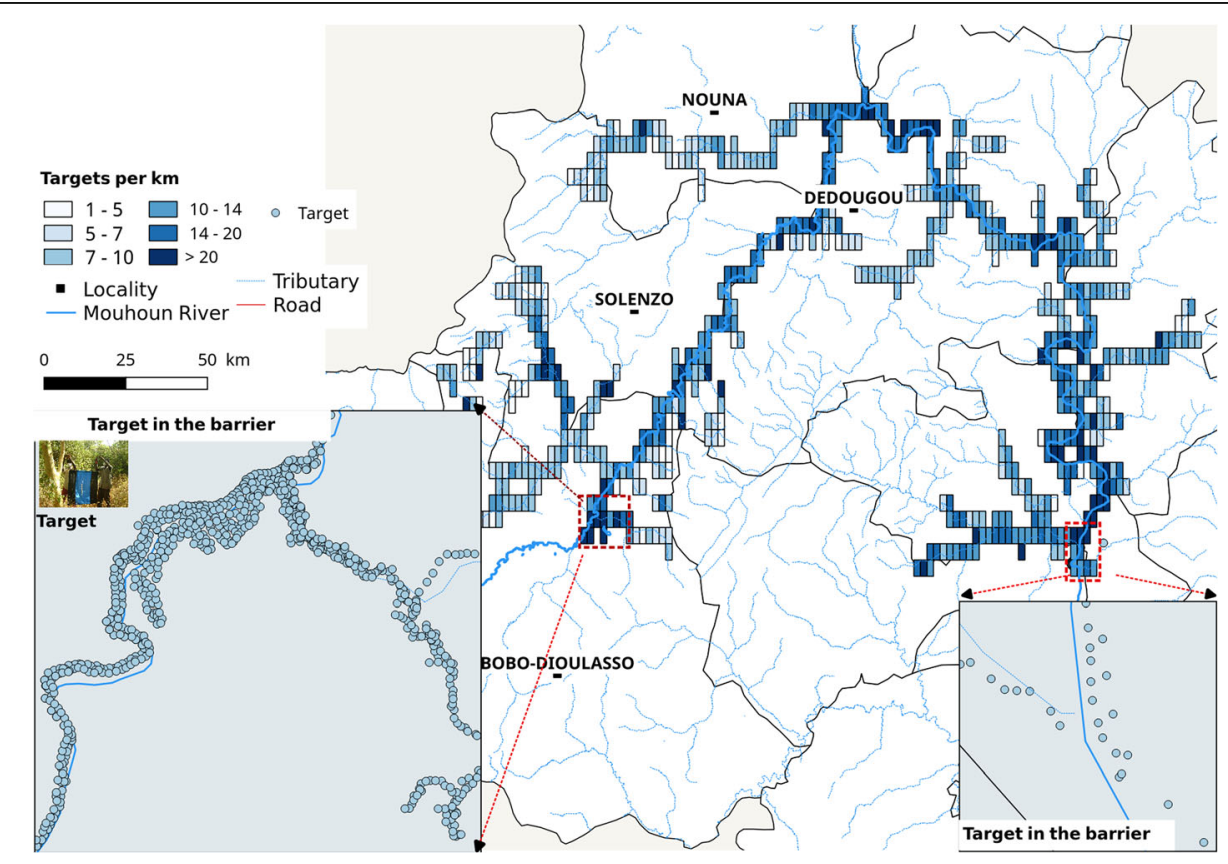

Fig. 2 Insecticide targets density along the Mouhoun River and its main tributaries 


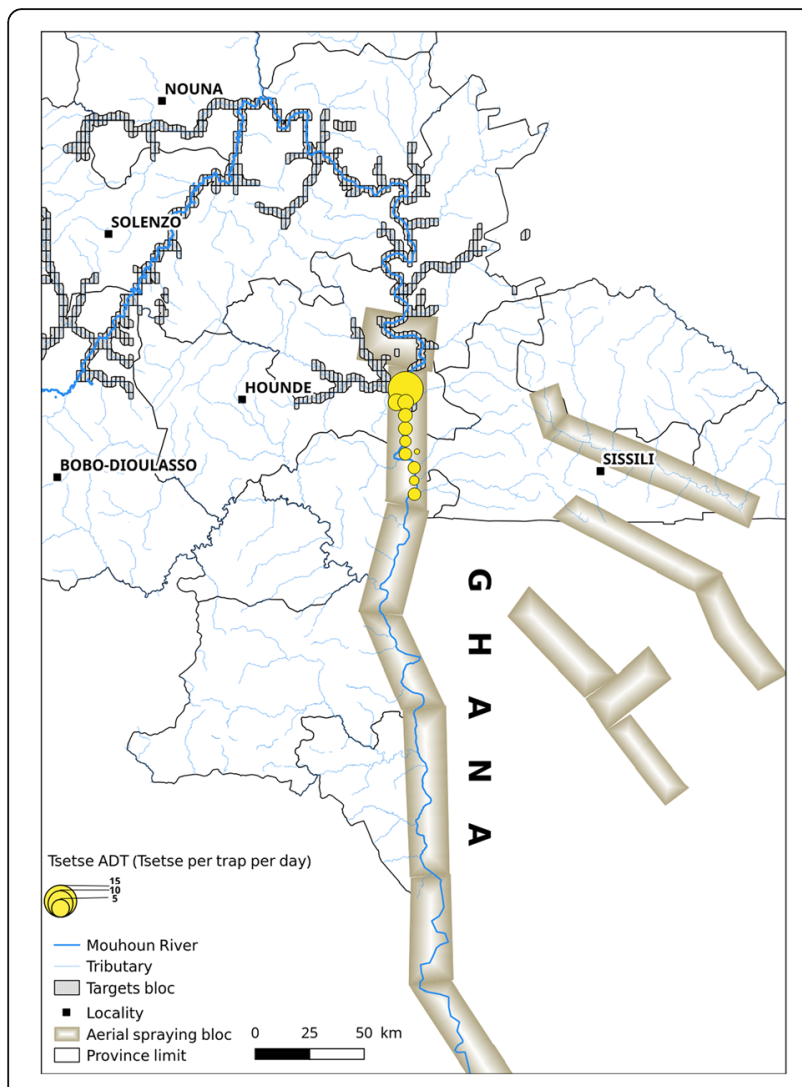

Fig. 3 Location of the sequential aerial spraying between Ghana and Burkina Faso

area on around $79 \mathrm{~km}$ of river. The campaign used special equipped airplanes hired from ORSMOND Aviation, South Africa [15]. In Burkina Faso, the SAT operations were conducted between 26th of March and 9th of May 2010 at the beginning of the rainy season. The applied insecticide was Deltamethrin $(0.35 \%(w / v)$, ultralow volume (ULV) (Deltanex formulation, Avima, Johannesburg, South Africa). Application rate was $0.33-0.35 \mathrm{~g}$ active ingredient (a.i)/ha at about $10 \mathrm{~m}$ above tree canopy [15]. The dispersal units were operated with cage speed of 11,000 rpm and an average flow rate of $9.7 \mathrm{l} / \mathrm{km}^{2}$ [15]. Temperature inversion was investigated at the airfield, but not in the gallery forest, using probes located at a height of approximately 1.5 and $8 \mathrm{~m}$. This inversion layer was shallow in the early afternoon, improving through the night and breaking down around 07:00 am [15]. Four weekly sequential aerial treatments were carried out. For the monitoring, entomological data were collected before and after spraying operations with a variable number of Challier-Laveissière traps. The raw data are presented in Additional file 1: Table S1.

\section{Ground spraying}

Ground spraying was used in the Satiri barrier area before every rainy season to reinforce it, in bushy areas and tsetse persistence zones at the end of project (Table 1). Some areas inaccessible from the ground were sprayed using a boat. Indeed, after the first phase of the generalized entomological survey (from 22nd January to 05th February 2013), tsetse seemed to persist on the "Siou River" and some of its tributaries in the western part of the intervention area (towards the border with Mali). A total of $4.08 \mathrm{~km}^{2}$ of gallery forest were sprayed three times from 10th to 24th March, 07th to 21st April and 05th to 12th May. Seven sites were chosen for monitoring with biconical traps before and after spraying. Insecticide was applied on ultra-low volume using Swingfog foggers (Isny, Germany; SN 50 and SN 101), or PortaPak sprayers and by nebulization with Mist Blowers at $3 \mathrm{~g} / \mathrm{ha}$. The insecticide used was deltamethrin, (Aqua-k-othrin ${ }^{\oplus}$, Leverkusen, Germany; $2 \%$ or K-Othrine 2.5\%). Fogging was applied early in the morning and late in the evening (after $4 \mathrm{pm}$ ).

\section{Trypanocide and epicutaneous mass treatment}

Mass epicutaneous (pour on and spray) and trypanocide treatment of cattle, sheep and donkeys was carried out by private veterinarians (Fig. 4). The main objective was to contribute to avoid trypanosomes transmission. The trypanocide treatment consisted to curative treatment with diminazene aceturate $(3.5 \mathrm{mg} / \mathrm{kg}$ b.w. deep intramuscular injection) followed by a preventive treatment three weeks period after with isometamidium $(1 \mathrm{mg} / \mathrm{kg}$

Table 1 Surface of treated zones by ground spraying

\begin{tabular}{|c|c|c|c|c|c|c|}
\hline \multirow[t]{2}{*}{ Treated zone } & & \multicolumn{2}{|c|}{ Length of river (km) } & \multirow[t]{2}{*}{ Swath width (m) } & \multirow[t]{2}{*}{ Total length treated $(\mathrm{km})$} & \multirow[t]{2}{*}{ Surface treated (ha) } \\
\hline & & Right bank & Left bank & & & \\
\hline \multirow[t]{2}{*}{ Barrier } & Mare aux hippopotames & 2 & 2 & 50 & 4 & 20 \\
\hline & Zangoma & 1 & 5 & 50 & 6 & 30 \\
\hline \multirow[t]{6}{*}{ Tsetse fly persistance zones } & Lery-Kouri & 10 & 10 & 50 & 20 & 10 \\
\hline & Dedougou & 8 & 8 & 50 & 16 & 80 \\
\hline & Darsalam & 4 & 4 & 50 & 8 & 40 \\
\hline & Tansila & 7.5 & 7.5 & 50 & 15 & 75 \\
\hline & Lery-Bouni & 14 & 14 & 50 & 28 & 140 \\
\hline & Siou river and its tributaries & 40.63 & 40.43 & 50 & 81.06 & 405.3 \\
\hline
\end{tabular}




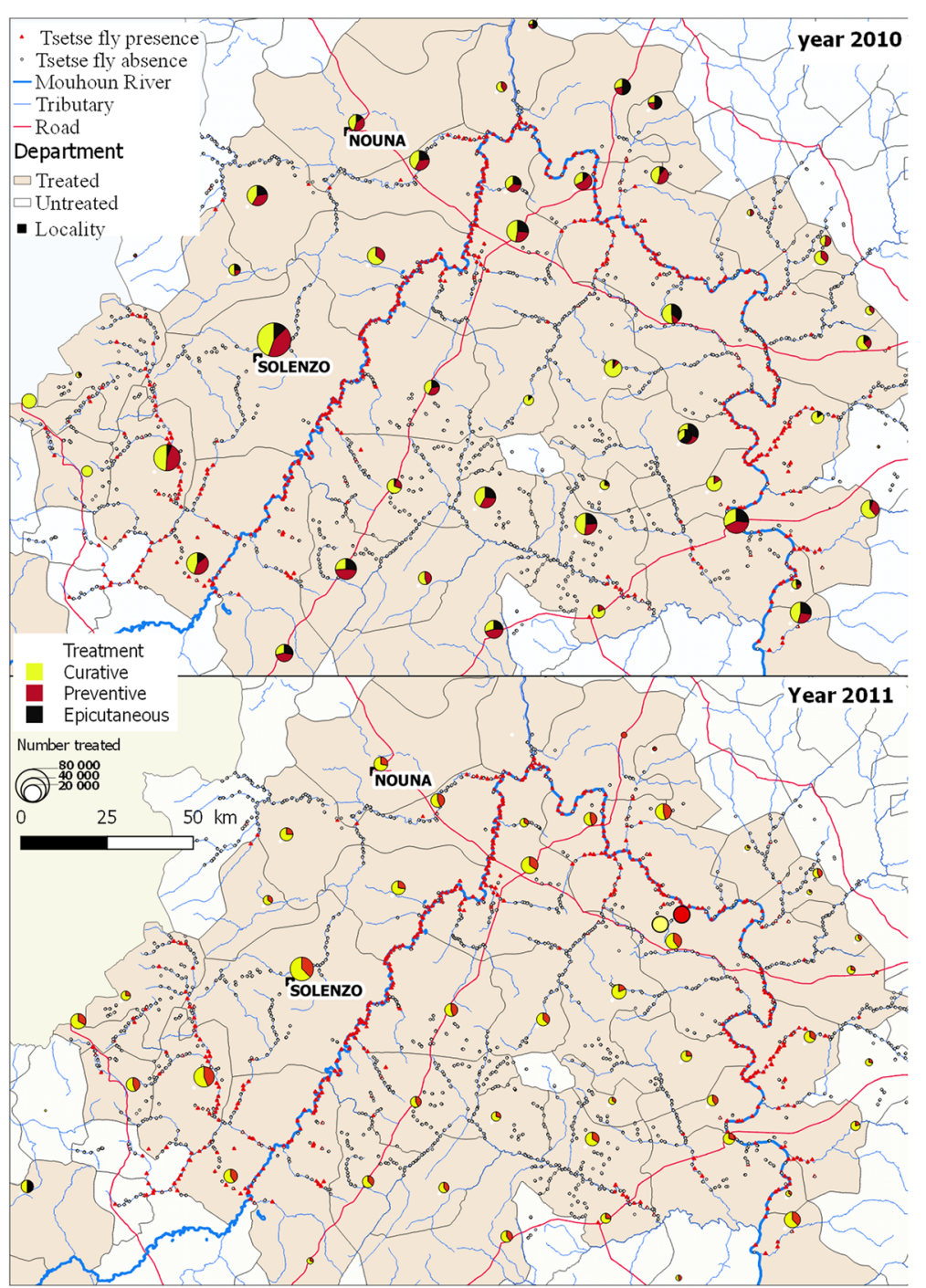

Fig. 4 Distribution of trypanocide and mass epicutaneous treatment of cattle in the study area

in $2 \%$ solution). Stockbreeders were required to apply epicutaneous treatments with cypermethrin $15 \mathrm{~g} / \mathrm{l}$. Treated animals constitute live baits for tsetse. It concerned the animals of villages located within a zone of $10 \mathrm{~km}$ on both sides of infested rivers. In 2010, all treatments were supported by PATTEC. The participation of the communities was on a voluntary basis. In 2011, only the cost of the trypanocides was financially supported by PATTEC; veterinarian's services had to be paid by farmers. The treatments were carried out during the rainy season (from June to December). More than one million animals were treated (Table 2).

\section{Periodical entomological survey}

More than 201 monitoring sites were selected based on the entomological baseline survey carried out from December 2007 to November 2008 [9]. Selection criteria were the abundance of tsetse flies (apparent densities per trap per day (ADT)) and the spatial relationship between sites (a maximum of 4 sites per square cell of $10 \times 10 \mathrm{~km}$ ) (Fig. 5). Every two months, two sentinel traps were set in each monitoring site. All trapping sites were georeferenced. To increase the attractiveness of the traps, a dispenser containing a 1:4:8 mixture of 3-n-propylphenol, 1-octen-3-ol and para-cresol was attached at the bottom of the trap. The pockets used to release the chemicals were made of $0.15 \mathrm{~mm}$ thick polyethylene measuring $4 \times$ $4 \mathrm{~cm}$, providing a diffusion surface of $32 \mathrm{~cm}^{2}$ [16]. Each pocket contained $2 \mathrm{ml}$ of mixture. In 2004, in an experience on the Sissili and Mouhoun River, this mixture increased the trapping of Glossina palpalis gambiensis and G. tachinoides, both Palpalis group flies, by a factor of two for both sexes compared to the trap alone [16]. Traps were set for 3 days before collection. Trapped insects were 
Table 2 Trypanocide and mass epicutaneous treatments in the control area

\begin{tabular}{|c|c|c|c|c|c|c|}
\hline \multirow[t]{2}{*}{ Year } & \multirow{2}{*}{$\begin{array}{l}\text { No. of } \\
\text { departments }\end{array}$} & \multirow{2}{*}{$\begin{array}{l}\text { No. of } \\
\text { producers }\end{array}$} & \multicolumn{4}{|c|}{ Number of animals $(n)$} \\
\hline & & & Curative treatments & Preventive treatments & Epicutaneous treatment & Total \\
\hline 2010 & 60 & 19,728 & 512,668 & 375,296 & 238,738 & $1,126,702$ \\
\hline 2011 & 59 & 10,799 & 380,088 & 208,799 & 60,064 & 648,951 \\
\hline
\end{tabular}

counted, identified by species and sex, and recorded in a data sheet. The raw data are presented in Additional file 2: Table S2.

\section{Longitudinal parasitological survey}

This study concerned sedentary cattle only. Based on the cross-sectional study in the PATTEC intervention area [17], 11 villages where the disease was more prevalent were selected for the longitudinal survey. However, two villages were abandoned later because of the absence of animals during the sampling periods and replaced by new ones. In each village, a sentinel herd of 50 cattle was selected. All sentinel animals were ear tagged. At the beginning of the survey, sampled cattle were treated with diminazene aceturate (DA), and dewormed with albendazole (Vermitan ${ }^{\circledR}$, CEVA, Libourne, France) $(7.5 \mathrm{mg} / \mathrm{kg}$ ). They received every two months a pour-on formulation mixing cypermethrin and amitraz (Cypertraz ${ }^{\circ}$ CEVA, Libourne, France) [18].

Before receiving any veterinary care or treatment, blood samples were collected from each animal through a jugular vein puncture with an EDTA tube for the detection of motile trypanosomes using the buffy coat technique [19]. Bimonthly monitoring surveys were carried out in all villages, in the view to check trypanosomosis infections in sentinel herds. During each survey, ill animals were treated with DA at the dose of $3.5 \mathrm{mg} / \mathrm{kg}$ b.w. Animals which missed one bimonthly follow-up were removed from the study onward. Sampling was also carried out on some calves in additional to the 50 heads of adult animals. To avoid self-medication by farmers, it was required from them to contact a PATTEC field veterinary technician who was made available throughout the study for any health care for the sentinel cattle.

\section{Final generalized (transversal) entomological survey}

From the beginning of tsetse control to December 2012, longitudinal entomological survey were conducted. At the end, in May 2013, a generalized control (transversal) was conducted in all areas. 401 sites found infested by tsetse before control were concerned.

\section{Data analysis}

Data were stored in a relational database to facilitate analysis. As described previously [20], we used a generalized linear mixed model [21] to measure the impact of

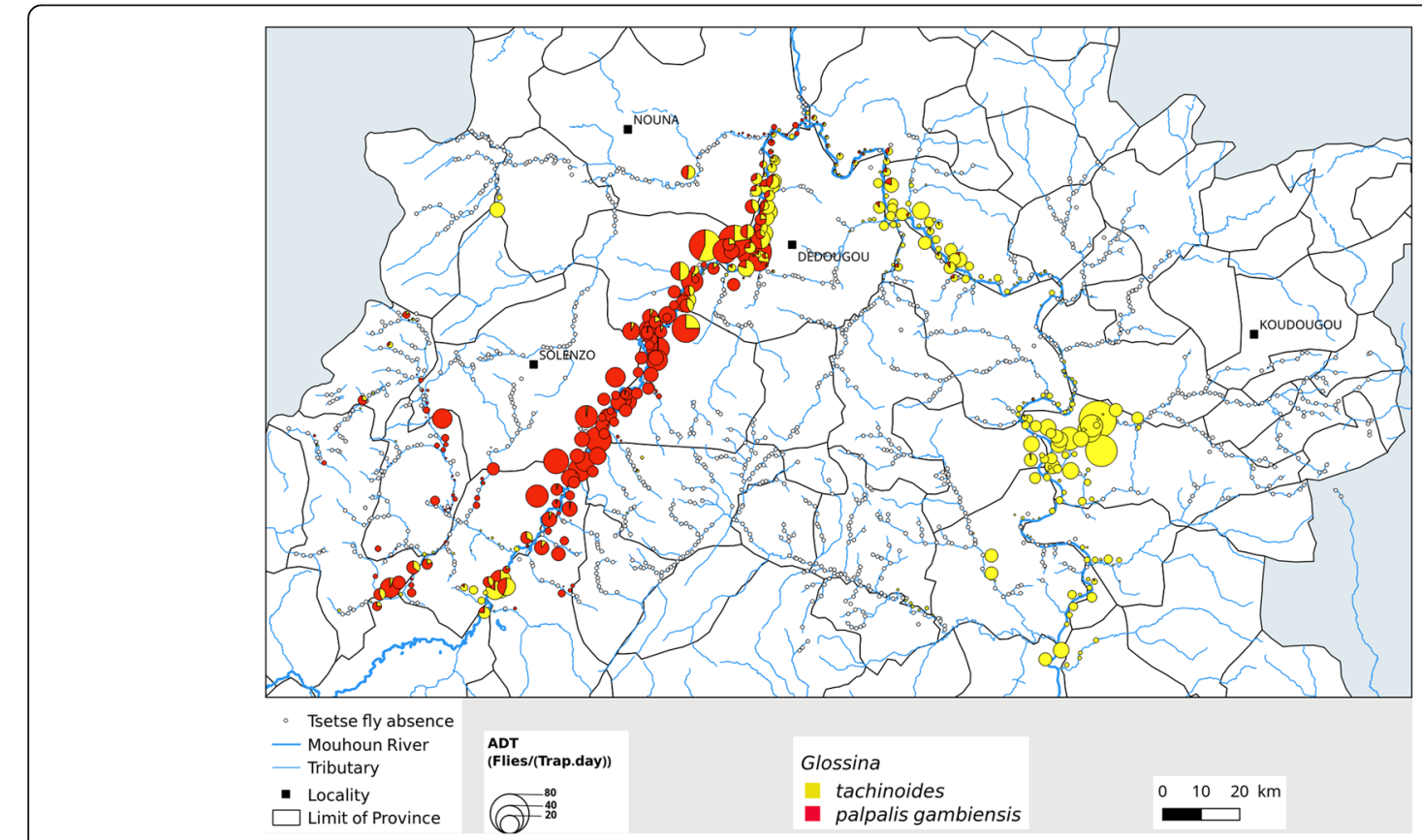

Fig. 5 Location of sentinel traps 

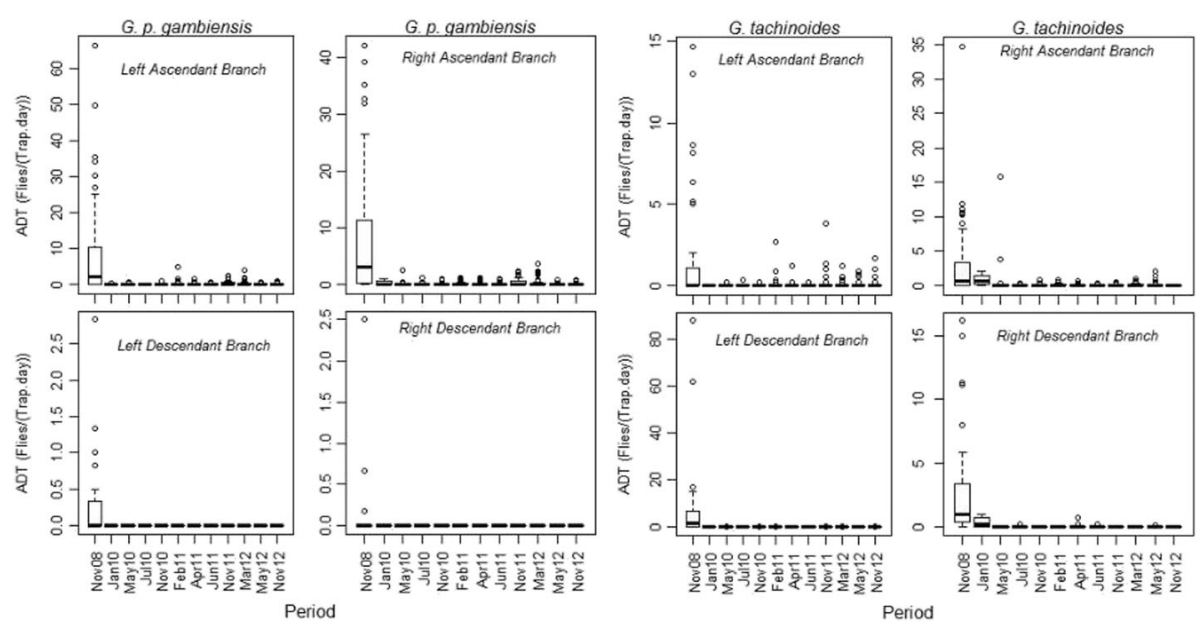

Fig. 6 Dynamics of tsetse apparent densities in the target area by river section. Tsetse densities during the fighting against tsetse fly in impregnated target area in different periods, the data are presented by species and river section. Boxplots present the median (bold line), quartiles (boxes), 95\% confidence intervals (horizontal lines) and erratic values (circles)

the suppression on tsetse apparent densities (ADT) and trypanosomosis prevalence. For ADT, the response data were tsetse apparent densities/trap/day. Time (measured in years), species (G. p. gambiensis and G. tachinoides), the river section ( $R A B$, right ascendant branch; $L A B$, left ascendant branch; LAB; RDB, right descendant branch; and LDB, left descendant branch), and their interactions were used as fixed effects, whereas the trap locations were used as random effects. Raw data for ADT are presented in Additional file 2: Table S2. For the trypanosomosis prevalence, time, locality and animal status (adult or calf) were used as fixed effects, whereas the animal numbers were used as random effect. Raw data for trypanosomosis prevalence are presented in Additional file 3: Table S3. For both analyses, the best model was selected on the basis of the lowest corrected Akaike information criterion (AICc), and the significance of fixed effects was tested using the likelihood ratio test $[22,23]$.

Moreover, the tsetse apparent densities (ADT) before and after the control campaign in the all area were compared using a paired Wilcoxon rank sum test for both species [24]. Raw data of these two surveys are presented in Additional file 4: Table S4.

\section{Results}

\section{Impregnated target distribution}

The maximum density of targets was $42 \mathrm{~km}^{2}$ with an average density of 3.12 (SD 3.32). The lowest densities were recorded in the lateral grid where tsetse infestations were weak and the highest on Mouhoun River different branches, especially at the top and the barriers. The density per $\mathrm{km}$ of river was 13.82 (SD 29.09).

\section{Longitudinal monitoring of tsetse densities}

The dynamics of tsetse apparent densities (ADT) in the monitoring system are shown in Fig. 5. Only two months after the setting of impregnated targets, the tsetse ADT dropped by more than $90 \%$. The rate of reduction reached 95\% within only 3 months of control. A high level of reduction of $99.77 \%$ was obtained in June 2011 for G. tachinoides and $99.84 \%$ in July 2010 for G. palpalis gambiensis. A new increase of the density of G. tachinoides was noted in the Left Ascendant Branch (LAB) from February 2011 to December 2012 (Fig. 6).

This reduction of the ADT with time was highly significant for both species (Table $3 ; P<0.0001$ ). The apparent density of G. palpalis gambiensis was overall higher than that of $G$. tachinoides at the beginning of the control campaign $(P=0.002)$ and dropped faster for this species $(P=0.004)$. Global tsetse densities were lower on the descendant branch and the tributaries located on

Table 3 Fixed-effect coefficients for the AlCc-best Linear mixed-effects model of the dynamics of tsetse apparent densities

\begin{tabular}{lllll}
\hline Parameters & Value & SE & $t$-value ${ }^{a}$ & $P$-value \\
\hline (Intercept) & 2.554 & 0.200 & 12.821 & $<0.0001$ \\
Time & -0.602 & 0.053 & -11.445 & $<0.0001$ \\
Species Gpg & 0.791 & 0.260 & 3.037 & 0.002 \\
Section LAB & 0.020 & 0.132 & 0.148 & 0.882 \\
Section RDB & -0.476 & 0.136 & -3.498 & 0.001 \\
Section LDB & -0.216 & 0.126 & -1.710 & 0.087 \\
Time: species Gpg & -0.212 & 0.074 & -2.846 & 0.004 \\
\hline
\end{tabular}

Degrees of freedom $=3895$

Glossina tachinoides were used as references for analysis

Abbreviations: Gpg Glossina palpalis gambiensis, $L A B$ left ascendant branch, $R D B$ right descendant branch, $L D B$ left descendant branch, $R A B$ right ascendant branch, SE standard error 
its right bank (RDB) than in the other river sections at the beginning of the control campaign (Table 3 ).

\section{Final generalized (transversal) entomological survey}

When comparing the densities before (October 2008) and after (May 2013) the control campaign in all those sites, where tsetse flies were present before the start of control operations, a strong reduction of ADT was observed (Fig. 6; $P<0.0001$ ). For G. palpalis gambiensis, ADT dropped from 3.337 (SD 7.998) to 0.565 (SD 2.795) (83\% reduction, Table 4, $P<0.0001$ ). For G. tachinoides, they dropped from 2.888 (SD 7.119), to 0.230 (SD 1.256) (92\% reduction, $P<0.0001$ ). In 2013 , tsetse flies were captured only in $29 \%$ of the sites found infested in 2008 . However, some high infestations were found in the Western part of the intervention area (Fig. 7).

\section{Impact of ground spraying on tsetse apparent density on the Siou River}

Some rates of reduction of 82.82 and $61.96 \%$ were noted one and three months after spraying for G. tachinoides, respectively, and 92 and $90 \%$ for G. palpalis gambiensis. Figure 8 shows the dynamics of densities.

\section{Impact of aerial spraying on tsetse ADT}

Only one species of tsetse fly, G. tachinoides was found around the aerial spraying area. Ten days before spraying, the apparent density per trap of tsetse was $4.38 \pm 6.01$. Ten days after the beginning, $52.63 \%$ reduction was noted. At the end of the project, 37 months after the spraying operation, ADT was $0.16 \pm 0.56$ (96.32\% reduction) (Table 5; Fig. 9).

\section{Dynamics of trypanosomosis prevalence in sentinel herds} A total of 7692 blood samples were taken from 790 animal heads (adults and calves) in 13 villages. A significant increase in the prevalence of mixed infections (T. vivax $+T$. congolensis) was observed over time (Fig. 10; Table 6). Calves were significantly less parasitized than adults $(P<0.0001)$. This increase was mainly observed in the village of Saint Michel $(P=0.004)$. For $T$. congolense, only transmitted by tsetse flies, there was also a significant increase in prevalence over time in sentinel herds. As for hematocrit, a significant decrease was observed during the survey $(P<0.0001)$.

Table 4 Results from comparisons of tseste ADT before and at the end of the project (one-tailed Wilcoxon signed rank test with continuity correction)

\begin{tabular}{lll}
\hline V-statistic (sum of positive ranks) & $P$-value & Test type \\
\hline 8701 & $<0.0001$ & Global \\
3176 & $<0.0001$ & G. palpalis gambiensis \\
8220 & $<0.0001$ & G. tachinoides \\
\hline
\end{tabular}

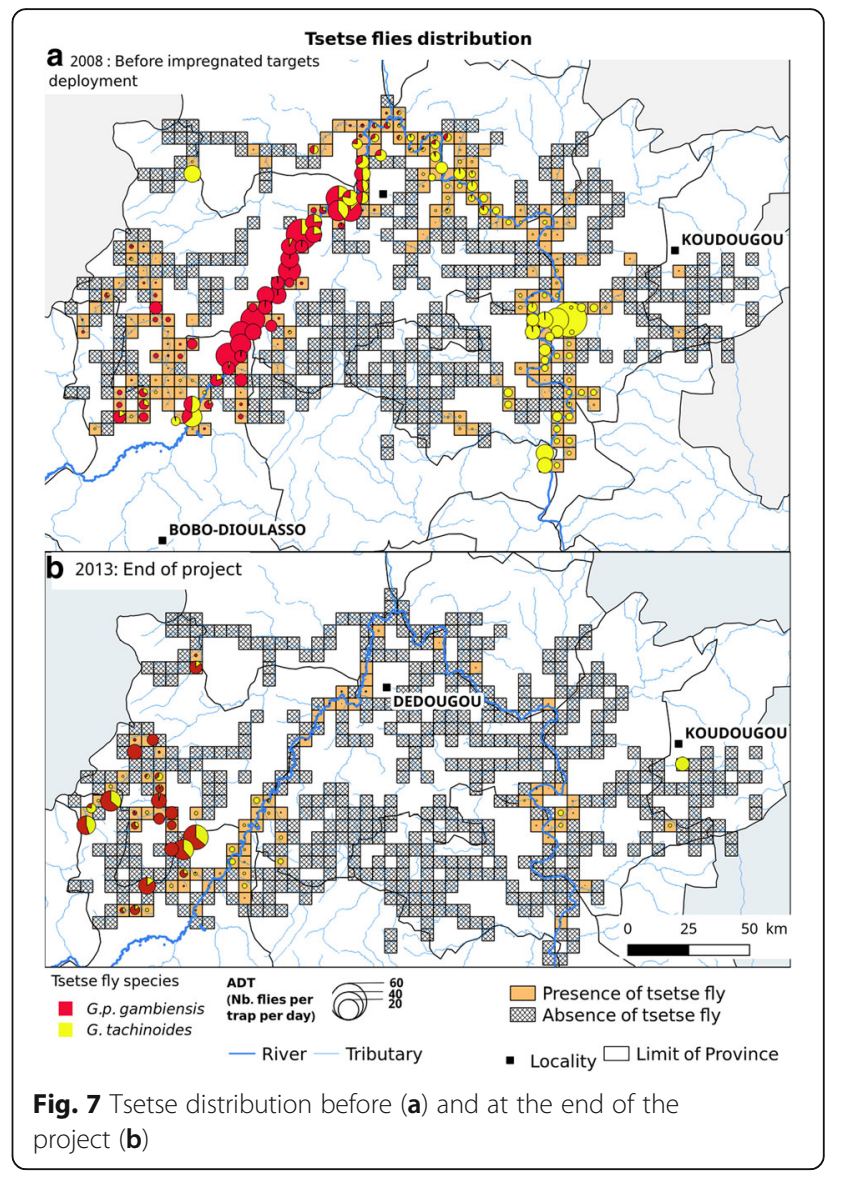

\section{Discussion}

The interest of traps and impregnated targets in tsetse control had been shown by Merot et al. [25]. In the PATTEC intervention area, a drastic reduction was obtained only after two months. These results confirm the well-established performance of impregnated insecticide targets reported elsewhere [23], and the effectiveness of beneficiary participation. Indeed, the involvement of beneficiary communities is an important point for the sustainability of the achievements of a control campaign $[4,10]$. More than 500 village auxiliaries, 955 department agents of Ministry of Resources of Animals and Halieutic (MRAH) participated in the fight and 75 tsetse controls comities were created in agro pastorals zones. Impregnated target effectiveness in tsetse control had been proved in Ivory Coast [26, 27], Burkina Faso in the pastoral zone of Yalé [2], the zones of Satiri and Padema, the agro-pastoral zone of Samorogouan, and in Hauts Bassins Region [10, 28, 29].

The high densities of targets in some areas were due to the existence of dense patches of Mimosa pigra or other abundant vegetation. The use of targets impregnated by the production factory represented an important asset. It not only reduced the work load but also the risk of pollution 


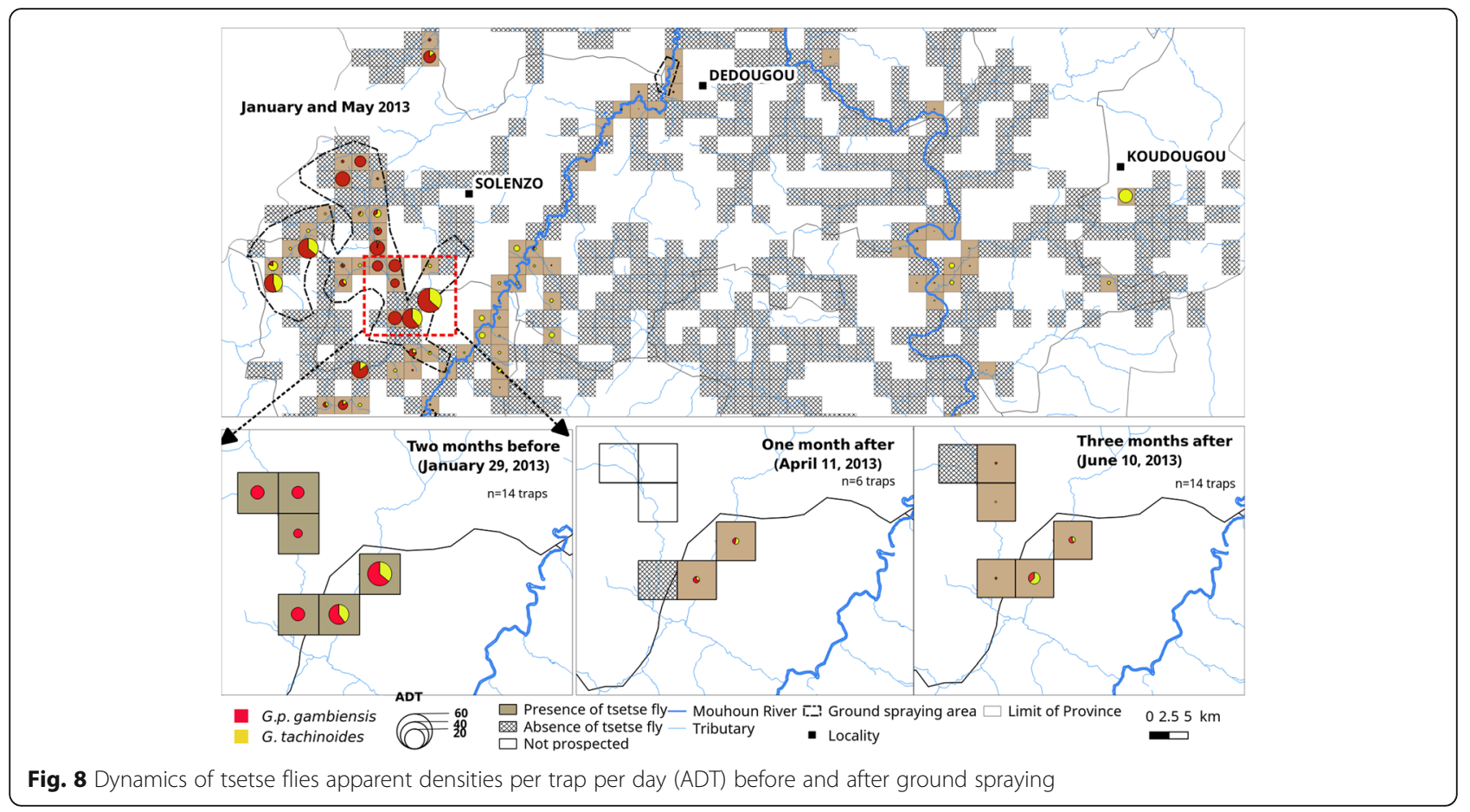

associated to re-impregnation. The only disadvantage was that they were a single use because of the $100 \%$ polyester fabric. The best result of re-impregnation is obtained with fabric composed of $67 \%$ polyester and $33 \%$ cotton. A re-impregnated test had yielded mixed results denounced by fishermen.

In the present study, the size of the target area and the installation of barriers were innovative and contributed to reduce quickly and drastically the number of flies at a wide scale. A paper is under preparation and will be submitted for publication soon. To measure the impact of the barrier, releases of sterile males were carried out at two distinct points inside and outside the barrier. Recaptures were done with 20 traps inside and 20 outside the barrier. We determined tsetse dispersal and showed that the barrier was efficient.

At the end of the project, tsetse apparent density was higher than the initial one on the Siou River, up to Mali. These results could be explained by insufficient community participation in control and maintenance of targets. Indeed, many targets were removed by communities; those which felled were not redeployed. The reinvasion could originate from untreated sites. A survey done after transversal surveys revealed tsetse presence in four untreated sites at Balavé (2), Padema (1) and Tansila (1). Ground spraying was then applied to reduce tsetse density before impregnated targets deployment.

Although more suitable in savanna areas, aerial spraying was successfully applied in gallery forest. This would be explained by the nature of the gallery not totally closed everywhere, spraying period, which corresponds to the temperature inversion times [30], and tsetse presence on upper parts of the leaves which made then vulnerable to insecticides [31]. However, we did not reach the reduction levels necessary to reach eradication (>98\% reduction of adult females at each cycle) [14].

The use of ground spraying and aerial spraying in ultra-low volume using no-residual insecticide allowed a fast reduction of tsetse fly densities. But a fast return towards the initial densities was observed if other strategies did not take over due to the absence of any residual effect of this method. Ground spraying requires more financial

Table $\mathbf{5}$ Impact of aerial spraying on tsetse density

\begin{tabular}{lllllll}
\hline Control & Period & No. of traps & Male & Female & Total & Reduction rate (\%) \\
\hline Before spraying & $16 / 03 / 10$ & 52 & $1.68 \pm 2.7$ & $2.70 \pm 3.6$ & $4.38 \pm 6.0$ & 0.00 \\
After 1st cycle & $06 / 04 / 10$ & 26 & $0.77 \pm 1.2$ & $1.31 \pm 1.4$ & $2.08 \pm 2.5$ & 52.63 \\
After spraying & $25 / 12 / 10$ & 69 & $0.03 \pm 0.1$ & $0.01 \pm 0.1$ & $0.04 \pm 0.2$ & 99.01 \\
& $10 / 12 / 11$ & 76 & $0.14 \pm 0.3$ & $0.11 \pm 0.3$ & $0.25 \pm 0.5$ & 94.20 \\
& $10 / 05 / 13$ & 62 & $0.09 \pm 0.3$ & $0.08 \pm 0.3$ & $0.16 \pm 0.6$ & 96.32 \\
\hline
\end{tabular}




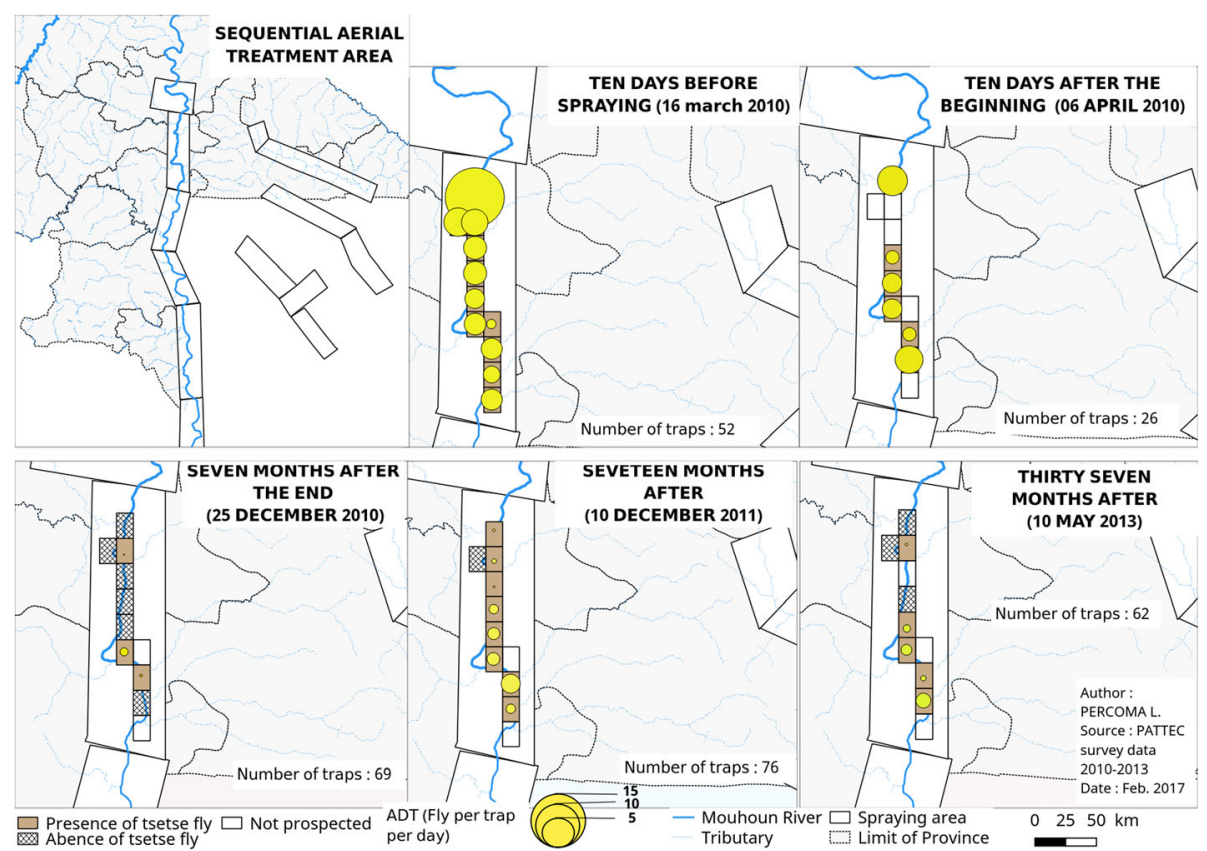

Fig. 9 Dynamics of tsetse apparent densities per trap per day (ADT) before and after aerial spraying

and human resources and may not be effective to treat large areas. But it has the advantage to be selective and can be used by non-experiment staff. It requires several successive treatments to be effective. Aerial spraying depends on weather conditions, which often makes it difficult to respect appropriated schedule. It also requires trained staff and special equipment. It does not promote community participation. Impregnated targets kept infestation at a very low level for 4 years. But this required regular maintenance of targets whatever the season. However, impregnated targets become less effective when tsetse densities become very low [20]. That would explain the absence of significant difference between ADT from the second to the last control period. The study showed the effectiveness of the integrated strategy to reduce tsetse populations but that no method can achieve eradication alone, as was observed recently in Senegal [20] and earlier in Burkina Faso [32].

The use of several strategies or techniques, including the sterile insect technique (SIT), could contribute to achieve the eradication of riverine tsetse species in the intervention area. An example eradication campaign was carried out in Unguja Island, Zanzibar from 1994 to 1996 using Area Wide Integrated Pest Management
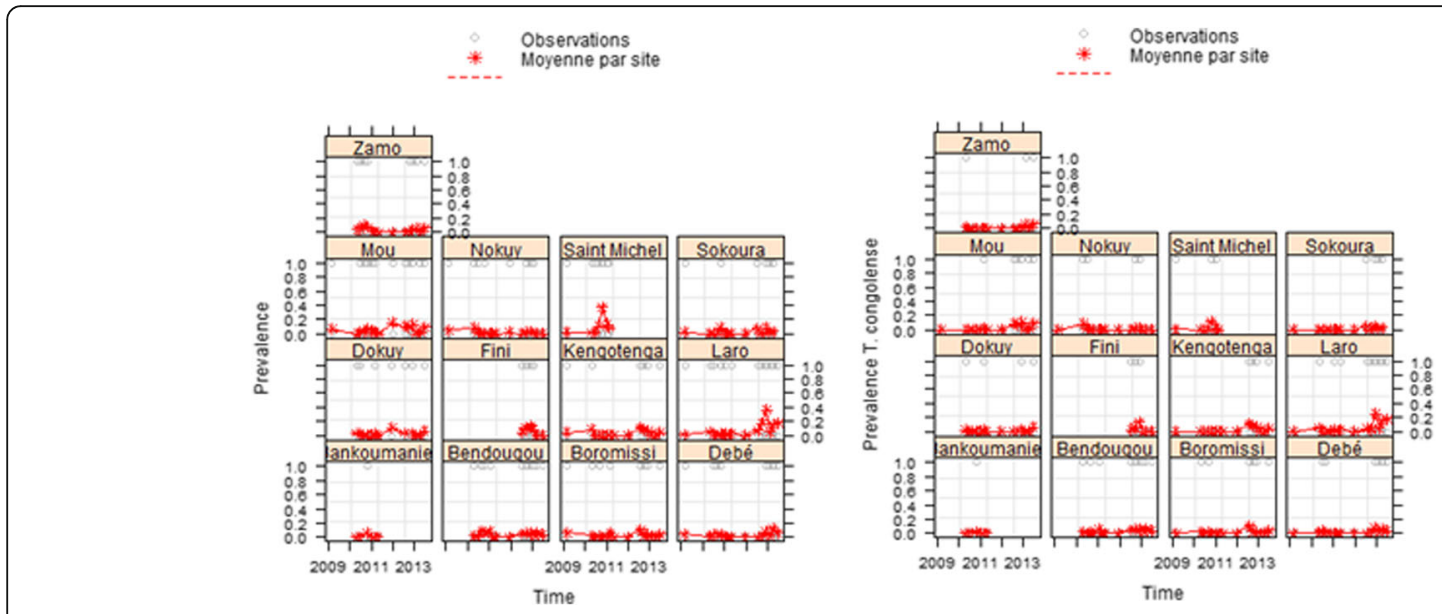

Fig. 10 Prevalence of trypanosomosis in the sentinel herds during the survey 
Table 6 Fixed-effect coefficients for the AlCc-best linear mixed-effects model of the trypanosomosis prevalence

\begin{tabular}{lllll}
\hline Parameters & Value & SE & $t$-value & $P$-value \\
\hline Intercept) & -13.800 & 2.288 & -6.030 & $<0.0001$ \\
Time & 0.001 & 0.0001 & 4.344 & $<0.0001$ \\
Loc Bendougou & 0.668 & 0.635 & 1.053 & 0.292 \\
Loc Boromissi & 0.409 & 0.636 & 0.643 & 0.520 \\
Loc Debé & 0.388 & 0.638 & 0.608 & 0.543 \\
Loc Dokuy & 0.043 & 0.676 & 0.064 & 0.949 \\
Loc Fini & 0.921 & 0.662 & 1.390 & 0.164 \\
Loc Kengotenga & 0.483 & 0.638 & 0.757 & 0.449 \\
Loc Laro & 1.370 & 0.613 & 2.235 & 0.025 \\
Loc Mou & 1.174 & 0.616 & 1.908 & 0.056 \\
Loc Nokuy & 0.183 & 0.645 & 0.284 & 0.776 \\
Loc Saint Michel & 1.910 & 0.619 & 3.085 & 0.002 \\
Loc Sokoura & 0.289 & 0.650 & 0.444 & 0.657 \\
Loc Zamo & 0.508 & 0.643 & 0.789 & 0.430 \\
Status Calve & -1.812 & 0.7622 & -2.377 & 0.017 \\
\hline Abbevatons Loclocity & SE stand
\end{tabular}

Abbreviations: Loc locality, SE standard error

(AW-IPM) approach with SIT component and tsetse pour-on applications of deltamethrin on livestock for tsetse population suppression. Before 1994, trypanosomosis prevalence and tsetse infestation had been reduced by pour-on in livestock abundant area and impregnated target at a density of densities of $40-70$ per $\mathrm{km}^{2}$ in areas where livestock was absent [33].

An increase of TAA prevalence was observed despite tsetse control. This may be explained by the integration of new animals in the sample, with animal movement from other tsetse infested sites. Indeed, 335 new animals were integrated to the survey during its course. Among them, $4.48 \%(n=15)$ were infected by TC, $1.75 \%(n=6)$ by TV and $0.30 \%(n=1)$ by TC and TV. This result might also be due to transmission by mechanical vectors, which are abundant in this area [34]. Indeed, it has been demonstrated that tabanides can transmit both $T$. vivax and $T$. congolense in this particular area $[35,36]$.

The Bobo mass-rearing insectary under construction is therefore a considerable asset for the country to achieve this eradication in the future. Recent experimental field release of gamma sterilized male G. p. gambiensis showed that their competitiveness might allow their use for an area-wide integrated pest management campaign with a sterile insect component in Burkina Faso [37].

To ascertain sustainability, PATTEC should sustain the efforts and reinforce the commitment of these beneficiary communities by creating and equipping village tsetse control committees with impregnated targets. The organization of regular tsetse fly monitoring and the transfer of some control activities to perennial structures, such as provincials or regionals directions of livestock, would also be beneficial. That justified the creation of "Insectarium de Bobo-Dioulasso - Campagne d'Eradication des Tsé-tsé et Trypanosomoses (IBD-CETT)”.

\section{Conclusions}

Impregnated targets such as aerial or ground spraying have resulted in a drastic reduction of tsetse flies, but without achieving elimination. None of these methods can therefore individually achieve eradication. They need to be integrated with other methods. This release could be started from 3 months after the setting of impregnated targets or immediately after spraying. The significant reduction achieved will result in improved animal productivity. Now in Burkina Faso, PATTEC need to maintain the present suppression status until the development of a tsetse colony big enough to allow the use of the sterile insect technique for eliminating the residual tsetse populations in the intervention area, as it was done elsewhere in Africa [38, 39]. It is the main challenge for the sustainability of the results. To do so, the continuous maintenance of the barriers, the permanent participation of the beneficiary communities and the continuous support from the national decision makers will be essential, as well as a sequential progression of the control activities towards the south, within a regional perspective.

\section{Additional files}

Additional file 1: Table S1. Database for Entomological survey of aerial spraying. (CSV $20 \mathrm{~kb}$ )

Additional file 2: Table S2. Database for the periodical control. (CSV $244 \mathrm{~kb}$ )

Additional file 3: Table S3. Data for trypanosomosis prevalence. (CSV $362 \mathrm{~kb}$ )

Additional file 4: Table S4. Database for the final longitudinal entomological survey. (CSV $62 \mathrm{~kb}$ )

\section{Abbreviations}

ADT: apparent density per trap per day; AlCc: Akaike information criterion; AU/PATTEC: African Union/Pan African Tsetse and Trypanosomosis Eradication Campaign; AW-IPM: Area Wide Integrated Pest Management; Gpg: Glossina palpalis gambiensis; Gt: Glossina tachinoides; IBD-CEIT: Insectarium de Bobo-Dioulasso - Campagne d'Eradication des Tsé-tsé et Trypanosomoses; LAB: Left ascendant branch; LDB: Left descendant branch; MRAH: Ministry of Resources of Animals and Halieutic; PATTEC: Pan African Tsetse and Trypanosomiasis Eradication Campaign; RAB: Right ascendant branch; RDB: Right descendant branch; SD: Standard deviation; ULV: Ultra-low volume; UTM: Universal Transverse Mercator coordinate system

\section{Acknowledgements}

We would like to display our gratitude to all the PATTEC-Burkina technicians, its focal points and the rural communities for their participation in the deployment of impregnated targets and the periodical entomological surveys. Special thanks to the Government of Burkina Faso and African Development Bank for finding the Campaign.

\section{Funding}

This study was carried out within the framework of the execution of PATTEC activities financed by the State of Burkina Faso through a loan contracted near 
African Development Bank. Loan reference was N²100150009193 - SAP nº P-Z1-AZ0-009.

\section{Availability of data and materials}

The datasets supporting the conclusions of this article are included within the article and its additional files.

\section{Authors' contributions}

$L P, A S, S P, J B$ and IS made substantial contributions to conception and design the study, LP, AS, SP, OS, LREB and IS collected the data; LP, AD, OS, JBR and JB analyzed the data; and LP, AS, SP, JB, AMG and IS participated in the writing the manuscript. All authors read and approved the final manuscript.

\section{Ethics approval and consent to participate}

This study was conducted in the framework of the Pan African Tsetse and Trypanosomosis Eradication Campaign (PATTEC) in Burkina Faso, led by the Ministry of Animal and Halieutic Resources and African Union/Pan African Tsetse and Trypanosomosis Eradication Campaign (AU/PATTEC) coordination office. The project received official approval from presidential decision $\mathrm{N}^{\circ}$ 2005-402/PRES/PM/MAECR/MS/MFB. For the insecticide aerial spraying, the official approval №009-00313/MRA/CAB was received from the Ministries of Animal Resources, Agriculture, Environment, Health and Defense.

\section{Consent for publication}

Not applicable

\section{Competing interests}

The authors declare that they have no competing interests.

\section{Publisher's Note}

Springer Nature remains neutral with regard to jurisdictional claims in published maps and institutional affiliations.

\section{Author details}

'Insectarium de Bobo-Dioulasso - Campagne d'Eradication des Tsé-tsé et Trypanosomoses (IBD-CETT), Bobo-Dioulasso 01 BP 1087, Burkina Faso. ${ }^{2}$ Centre International de Recherche-Développement sur l'Elevage en Zone Subhumide (CIRDES), Bobo-Dioulasso 0101 BP. 454, Burkina Faso. ${ }^{3}$ Ecole Inter-Etats des Sciences et Médecine Vétérinaires (EISMV), Laboratoire d'Endocrinologie et de Radio-Immunologie, BP. 5077 Dakar Fann, Senegal. ${ }^{4}$ CIRAD, UMR ASTRE CIRAD-INRA « AnimalS, health, Territories, Risks and Ecosystems », Campus international de Baillarguet, 34398 Montpellier cedex 05, France. ${ }^{5}$ Humanitarian Data Exchange (HDX) - humdata.org, OCHA ROWCA regional office. VDN Sacre Coeur III, Villa 9364 BP 16 922, Fann Dakar, Senegal. 'aboratoire Régional d'Elevage de Bobo-Dioulasso, Bobo-Dioulasso 0101 BP 345, Burkina Faso. ${ }^{7}$ CIRAD, UMR INTERTRYP, F-34398 Montpellier, France. ${ }^{8}$ Université Polytechnique de Bobo-Dioulasso, Bobo-Dioulasso, Burkina Faso.

\section{Received: 17 May 2017 Accepted: 28 December 2017} Published online: 27 April 2018

\section{References}

1. Cuisance $D$, Politzar $H$, Mérot $P$, Tamboura I. Les lâchers de mâles irradiés dans la campagne de lutte intégrée contre les glossines dans la zone pastorale de Sidéradougou, Burkina Faso. Rev Elev Méd Vét Pays Trop. 1984; 37:449-67.

2. Bauer B, Amsler-Delafosse S, Kaboré I, Kamuanga M. Improvement of cattle productivity through rapid alleviation of African animal trypanosomosis by integrated disease management practices in the agropastoral zone of Yalé, Burkina Faso. Trop Anim Health Prod. 1999;31:89-102.

3. Kamuanga M, Swallow BM, Sigué H, Bauer B. Evaluating contingent and actual contributions to a local public good: tsetse control in the Yale agropastoral zone. Burkina Faso Ecol Econ. 2001;39:115-30.

4. Sow A, Sidibé I, Bengaly Z, Bouyer J, Bauer B, Van den Bossche P. Fifty years of research and fight against tsetse flies and animal trypanosomosis in Burkina Faso. An overview. Bull Anim Health Prod Afr. 2010:58:95-118.

5. Région de la Boucle du Mouhoun; Cadre stratégique Régional de Lutte contre la pauvreté, Ouagadougou, Burkina Faso. Rapport du Ministère de I'Economie et du Développement du Burkina Faso (MEDEV), 1-106.
6. Ministère des Ressources Animales (MRA). Les Statistiques du Secteur de l'Elevage au Burkina Faso. Ouagadougou, Burkina Faso; 2008. p. 124

7. Dicko AH, Percoma L, Sow A, Adam Y, Mahama C, Sidibé I, et al. A spatio-temporal model of African animal trypanosomosis risk. PLoS Negl Trop Dis. 2015;9:e0003921.

8. Percoma L, Koudougou Z, Serdébéogo O, Tamboura I, Ouédraogo M, Bouyer J, et al. Enquêtes entomologiques préparatoires à une lutte à grande échelle contre les glossines, assistées par un système d'information géographique : cas de la PATTEC au Burkina Faso. Anim Health Prod. 2015; 68:157-65.

9. Pan African Tsetse and Trypanosomiasis Eradication Campaign (PATTEC) Resultats entomologiques de base dans le bassin du mouhoun. Rapport final. Bobo-Dioulasso, Burkina Faso; 2008, p. 57.

10. Bauer B, Amsler-Delafosse S, Clausen PH, Kabore I, Petrich-Bauer J. Successful application of deltamethrin pour on to cattle in a campaign against tsetse flies (Glossina spp.) in the pastoral zone of Samorogouan, Burkina Faso. Trop Med Parasitol. 1995:46:183-9.

11. Bouyer J, Ravel S, Dujardin JP, De Meeüs T, Vial L, Thévenon S, et al. Population structuring of Glossina palpalis gambiensis (Diptera: Glossinidae) according to landscape fragmentation in the Mouhoun River, Burkina Faso. J Med Entomol. 2007:44:788-95.

12. Bouyer J, Balenghien T, Ravel S, Vial L, Sidibé I, Thévenon S, et al. Population sizes and dispersal pattern of tsetse flies: rolling on the river? Mol Ecol. 2009;18:2787-97.

13. Koné N, Bouyer J, Ravel S, Vreysen MJB, Domagni KT, Causse S, et al. Contrasting population structures of two vectors of African trypanosomoses in Burkina Faso: consequences for control. PLoS Negl Trop Dis. 2011;5:e1217.

14. Kgori PM, Modo S, Torr SJ. The use of aerial spraying to eliminate tsetse from the Okavango Delta of Botswana. Acta Trop. 2006;99:184-99.

15. Adam Y, Cecchi G, Kgori PM, Marcotty T, Mahama Cl, Abavana M, et al. The sequential aerosol technique: a major component in an integrated strategy of intervention against riverine tsetse in Ghana. PLoS Negl Trop Dis. 2013;7: e2135.

16. Rayaisse JB. Development of tools to control Palpalis group tsetse flies in West Africa. PhD Thesis, Université de Neuchâtel, Switzerland; 2011.

17. Sow A, Sidibé I, Bengaly Z, Marcotty T, Séré M, Diallo A, et al. Field detection of resistance to isometamidium chloride and diminazene aceturate in Trypanosoma vivax from the region of the boucle du Mouhoun in Burkina Faso. Vet Parasitol. 2012;187:105-11.

18. Gimonneau G, Alioum Y, Abdoulmoumini M, Zoli A, Cene B, Adakal H, et al. Insecticide and repellent mixture pour-on protects cattle against animal trypanosomosis. PLoS Negl Trop Dis. 2016;10:e0005248.

19. Murray M, Murray PK, Mcintyre WI. Improved parasitological technique for diagnosis of African trypanosomiasis. Trans R Soc Trop Med Hyg. 1977;71:325-6.

20. Dicko AH, Lancelot R, Seck MT, Guerrini L, Sall B, Lo M, et al. Using species distribution models to optimize vector control in the framework of the tsetse eradication campaign in Senegal. Proc Natl Acad Sci U S A. 2014;111:10149-54.

21. Laird NM, Ware JH. Random-effects models for longitudinal data. Biometrics. 1982;38:963-4.

22. Hurvich CM, Tsai CL. Model selection for extended quasi-likelihood models in small samples. Biometrics. 1995;51:1077-84.

23. Burnham KP, Anderson DR. Multimodel inference: understanding AIC and BIC in model selection, Colorado Cooperative Fish and Wildlife Research Unit (USGS-BRD). Sociological methods \& research. 2004;33:261-304.

24. Hollander M, Wolfe DA. Nonparametric statistical methods. New York: Wiley; 1973

25. Merot P, Politzar H, Tamboura L, Cuisance D. Résultats d'une campagne de lutte contre les glossines riveraines en Burkina par l'emploi d'écrans imprégnés de deltaméthrine. Rev Elev Méd Vét Pays Trop. 1984;37:175-84.

26. Laveissière $\mathrm{C}$, Couret $\mathrm{D}$, Traore $\mathrm{T}$. Tests d'efficacité et de rémanente d'insecticides utilisés en imprégnation sur tissus pour la lutte par piégeage contre les glossines. O.R.S.T.O.M. Sér Ent Méd et Parasitol. 1985;23:61-7.

27. Gouteux J-P, Challier A, Laveissière C, Couret D. L'utilisation des écrans dans la Lutte anti-tsetse en zone forestière. Tropenmed Parasitol. 1982;33:163-8.

28. Bauer B, Kaboré I, Liebisch A, Meyer F, Petrich-Bauer J. Simultaneous control of ticks and tsetse flies in Satiri, Burkina Faso, by the use of flumethrin pour on for cattle. Trop Med Parasitol. 1988;43:41-6.

29. Bontoulougou J, Oulé JM, Pellissier JP, Tallet B. La participation des acteurs, un exercice difficile. Leçons de l'expérience d'un plan de lutte contre la trypanosomose animale africaine dans la vallée du Mouhoun (Burkina Faso). Rev Nat Sci Sociétés. 2000;8:33-43. 
30. Hursey BS. Lutte contre les glossines en Afrique. Rev Sci Tech Off Int Epiz. 1985:4:299-310

31. Kupper W, Koch K. Les gites de repos nocturne de Glossina spp. (Diptera: Glossinidea) dans I'Ouest de la Haute-Volta. I. Glossina tachinoides. Rev Elev Méd Vét Pays Trop. 1983;36:175-81.

32. Cuisance D, Politzar H, Fevrier J, Bourdoiseau G, Sellin E. Association d'un traitement insecticide avec la méthode du mâle stérile contre Glossina palpalis gambiensis : intérêt de la mise en oeuvre de plusieurs méthodes. Rev Elev Méd Vét Pays Trop. 1980;33:127-33.

33. Vreysen MJB, Saleh K, Mramba F, Parker A, Feldmann U, Dyck VA, et al. Sterile insects to enhance agricultural development: the case of sustainable tsetse eradication on Unguja Island, Zanzibar, using an area-wide integrated pest management approach. PLoS Negl Trop Dis. 2014;8(5):e2857.

34. Koné N, N'goran EK, Sidibe I, Kombassere AW, Bouyer J. Spatio-temporal distribution of tsetse and other biting flies in the Mouhoun River basin, Burkina Faso. Med Vet Entomol. 2011;25:156-68.

35. Desquesnes M, Dia ML. Trypanosoma vivax: mechanical transmission in cattle by one of the most common African tabanids, Atylotus agrestis. Exp Parasitol. 2003;103:35-43.

36. Desquesnes M, Dia ML. Mechanical transmission of Trypanosoma congolense in cattle by the African tabanid Atylotus agrestis. Exp Parasitol. 2003;105:226-31.

37. Sow A, Sidibe I, Bengaly Z, Bancé AZ, Sawadogo GJ, Solano P, et al. Irradiated male tsetse from a 40-year-old colony are still competitive in a riparian forest in Burkina Faso. PLoS One. 2012;7:e37124.

38. Vreysen MJB, Saleh KM, Ali MY, Abdulla AM, Zhu Z-R, Juma KG, et al. Glossina austeni (Diptera: Glossinidae) eradicated on the island of Unguja, Zanzibar, using the sterile insect technique. J Econ Entomol. 2000;93:123-35.

39. Vreysen MJB, Seck MT, Sall B, Bouyer J. Tsetse flies: their biology and control using area-wide integrated pest management approaches. J Invertebr Pathol. 2013;112:15-25.

\section{Submit your next manuscript to BioMed Central and we will help you at every step:}

- We accept pre-submission inquiries

- Our selector tool helps you to find the most relevant journal

- We provide round the clock customer support

- Convenient online submission

- Thorough peer review

- Inclusion in PubMed and all major indexing services

- Maximum visibility for your research

Submit your manuscript at www.biomedcentral.com/submit 